T. HATAKEYAMA, R. IMAYOShi, Y. YOSHIMOTO, S. K. GHORAI, M. JIN, H. TAKAYA, K. NORISUYE, Y. SOHRIN, M. NAKAMURA* (KYOTO UNIVERSITY AND JAPAN SCIENCE AND TECHNOLOGY AGENCY, TOKYO, JAPAN)

Iron-Catalyzed Aromatic Amination for Nonsymmetrical Triarylamine Synthesis

J. Am. Chem. Soc. 2012, 134, 20262-20265.

\section{Iron-Catalyzed Amination of Aromatic Bromides}

Category

Metal-Mediated

Synthesis

Key words

iron

amination

triarylamines

SYNFACT Then

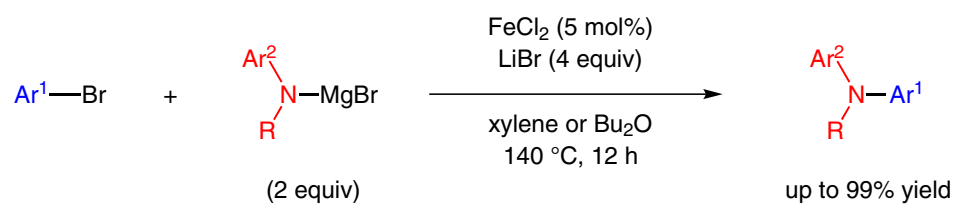

$\mathrm{Ar}^{1}=\mathrm{Me}, \mathrm{OMe}, \mathrm{NMe}_{2}, \mathrm{Cl}$ - and F-substituted (hetero)aromatics

$\mathrm{Ar}^{2}=\mathrm{Ph}, 4-\mathrm{Tol}$, 3-Tol, 4- $\mathrm{FC}_{6} \mathrm{H}_{4}$

$\mathrm{R}=\mathrm{Ph}, 4-\mathrm{Tol}, \mathrm{TMS}$

Selected examples:

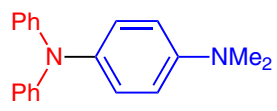

$88 \%$ yield

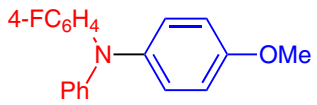

$82 \%$ yield

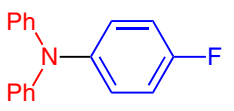

$77 \%$ yield

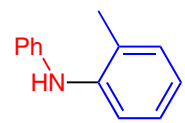

$76 \%$ yield

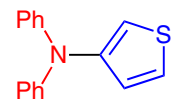

$61 \%$ yield<smiles>c1ccc(Nc2ccccn2)cc1</smiles>

$98 \%$ yield

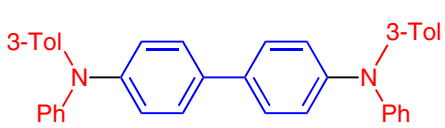

$82 \%$ yield
Significance: A novel iron-catalyzed amination reaction of aryl bromides with in situ generated magnesium amides has been disclosed. This new protocol proceeds in xylene or dibutyl ether at elevated temperatures in the presence of lithium bromide and provides diaryl- and triarylamines without the use of expensive and/or toxic metals.
Comment: The authors propose the following mechanism: $\mathrm{FeCl}_{2}$ reacts with two equivalents of magnesium amide to form monomeric and dimeric iron(II)-diamide complexes, which are in equilibrium with each other. The monomer undergoes an oxidative addition with the aryl bromide to form an iron(IV) intermediate. Reductive elimination affords the product and an iron(II)-monoamide complex. Regeneration of the active species via $\mathrm{LiBr}$-assisted transmetalation with the magnesium amide completes the cycle. 